\title{
Social Networks: A Curse or a Blessing? (A Case Study of Selected Students from Auchi Polytechnic)
}

\author{
${ }^{1}$ Uduiguomen Usifoh Collins, ${ }^{2}$ Agwi Uche Celestine and ${ }^{1}$ Aliu Nefishetu Faith \\ ${ }^{1}$ Department of Computer Science, Auchi Polytechnic, Auchi, Edo State, Nigeria. \\ ${ }^{2}$ Department of Mathematical and Physical Sciences, Samuel Adegboyaga University, Ogwa, \\ Edo State, Nigeria. \\ mailusifoh@yahoo.com ; ucheworld2002@yahoo.com ; aliunefishetufaith@yahoo.com
}

\begin{abstract}
This paper presents the findings from an investigation into the question whether a social network is a blessing or a curse. We used a sample population of 320 students at Auchi Polytechnic, Auchi in Edo Sate Nigeria as our case study. This investigation was borne out of the ever-increasing interest that a lot of people are expressing in their fraternity with the various social networks and the obvious opportunities and prospects as well as the virtues and vices these social networks portend. Social networks are like legal tenders; on their own, they are neither good nor bad. What defines them and gives them their characteristics are what a user does with them. A lot of unsavory activities (ranging from fraud, identity theft to outright blackmail) have been known to be carried out using social networks as a platform but in retrospect, varying degrees of positive achievements (such as building of mutually beneficial relationships and ties, reestablishment of lost contacts and effective communication) has also been recorded using social networks. From the investigation that we carried out, it was observe that social network can serve as a blessing and it can also serve as a curse depending on how and what a user use it for.
\end{abstract}

Keywords: Social networks, Facebook, Twitter, 2go, Eskimi, Naijapals, Gnaija.

\section{Introduction}

Social networks like Facebook, twitter and others have provided a platform where people communicate, make friends, meet old friends, share ideas, share photos and so on. Social media is all around us and it has come to encompass every aspect of our lives. Social networks have been very useful to almost everyone across the globe especially the youth. These social sites have created the platform for both the young and old to do so many things which would have been impossible without the presence of these sites. Many making new friends, others finding old friends and reconnecting. Some users have found boyfriends and girlfriends and 
even life partners thus to talk of a few. Business men and women are using these sites to advertise and market their products and services with ease. Social media has contributed immensely to the development of arts especially musicians. Musicians are using social media sites to interact with their fans and also putting up download links for people to download their music. Aside musicians, prominent pastors also use these sites to win souls for Christ. In the recently held general elections in the USA and in Nigeria, facebook and twitter were particularly the dominant social sites [1]. Prior to the gubernatorial July 14th, 2012 election that was held in edo state, nigeria, a lot of persons and corporate bodies were using the facebook social network to advice stakeholders on various issues as they relate to the conduct of the election [2].

Generally, a lot of interesting activities takes place on these social sites daily. Among all these advantages lies the bad side of social networks. Social media have been of very good use to society since its invention but there have been some abuses or disadvantages in relation to these sites. Impersonation has been a common abuse of the social media which some fraudulent minds has been using to misrepresent themselves to others especially celebrities to perpetrate fraud on others. Also social vices such as prostitution, fraud among others have always existed [1]. Akinwale cited a case that involved one Cynthia Ozokogu, 24, the last child and only daughter of major general Ozokogu (rtd). She was killed on July 22, 2012 in a hotel in Festac, Lagos state by so-called friends that she met on facebook. Her alleged killers have been arraigned for murder [3].

The Associated Press reported on the 1st of May, 2013 that in the early days of the evolution of social networking websites there were four major social networking sites in common use. They were Facebook, LinkedIn, MySpace and Twitter. Facebook, was introduced in February 2004 and is one of the most popular social networking websites today. This website was originally open only to students at Harvard University, but this no longer holds true. As at March 1, 2013, Facebook said it had 1.11 billion people using the site each month.

Linkedin was started in May 2003, and is less focused on social networking. This tool is used to network within a desired professional atmosphere and allows individuals to build professional, career-oriented relationships. Linkedin is the most business-oriented of the four big social networking websites. Hempel hinted that as of June 2013, LinkedIn has more than 225 million members in over 200 countries and territories [5].

MySpace was founded in August 2003. It is more directed toward the musically inclined. This social networking website is no longer solely for social networking. It is more about connecting different bands and groups, rather than connecting individuals. The membership for MySpace is about 126 million. 


\section{Background to the Study}

From the Auchi Polytechnic student handbook of information, Auchi Polytechnic, Auchi is a government tertiary institution owned by the federal government of Nigeria. The polytechnic is located in Edo State of Nigeria. The polytechnic is home to students from different socioeconomic background and different ethnicities within Nigeria. The Polytechnic was established to provide for studies, training and development of techniques in applied sciences, engineering, art and business as well as in other spheres of learning, cultural development and the inculcation of good character which are integral parts of education and training. The unity in diversity that the Polytechnic exudes is apparent in all segments of her operations [9]. Though the Polytechnic has its share of challenges that ranges from infrastructural deficiency to inadequate manpower to tackle the rigors that are prevalent in similar institutions of learning, most students and staff are still actively involved in the use of social networks here for one activity or the other.

From a new demographic breakdown by the Pew Research Institute, it was shown that the majority of social media users lives in the city and prefers Facebook as their main medium. The breakdown, which was based on a late 2012 survey, also showed that young adults are, unsurprisingly, the most likely group to use major social media. While internet users under the age of 50 are more likely to use any social networking site, those in the 18-29 age group are the most likely at 83 percent [10].

Taking a clue from the result of the Pew Research Institute survey, we decided to do a survey in the Polytechnic to ascertain possible outcome from our students and as it turned out, the cooperation was massive. Most of the students in the Polytechnic had one or more social network account.

\section{Methodology and Materials}

The data used was derived from the responses that were received from a total of 320 respondents who were able to properly answer and return the questionnaires that were administered. Initially, 350 questionnaires were prepared but in the course of their administration and collation only 320 were selected as meeting the minimum standard that was set for the questionnaire acceptability. One of the criterion that was used to screen out some respondents was their response to the question "Do you own an account with any social network site like Facebook, Twitter, 2go or any other?" Ten questions including the benchmark question above were however contained in the questionnaire to elicit information from the respondents.

For the analysis of data we used the simple percentage method. The decision rule that was used is the acceptance of majority of opinion or high percentage. In view of the nature of this 
investigation, detailed data representation of the responses we got from six (6) out of the ten (10) items in our questionnaire are presented below.

Table 1 shows the response we got when we asked from the sample population the question "Which social network do you use?"

\begin{tabular}{|c|c|c|c|}
\hline Question & Social network & Respondents & Percentage (\%) \\
\hline Which social & Facebook & 192 & 60 \\
network do you use? & & 49 & 15.31 \\
\cline { 2 - 4 } & Twitter & 69 & 21.56 \\
\cline { 2 - 4 } & 2go & 10 & 3.13 \\
\cline { 2 - 4 } & Any other & & \\
\hline
\end{tabular}

Table 2, presented the response we got to the question "How many social network accounts do you have from the entire social network combined?"

\begin{tabular}{|c|c|c|c|}
\hline Question & Options & Respondents & Percentage (\%) \\
\hline How many & $1-3$ accounts & 220 & 68.75 \\
\cline { 2 - 4 } social network & $4-6$ accounts & 85 & 26.56 \\
\cline { 2 - 4 } $\begin{array}{c}\text { accounts do you } \\
\text { have from the } \\
\text { entire social } \\
\text { network combined? }\end{array}$ & 7 and above & 15 & 4.69 \\
\hline
\end{tabular}

Table 3 indicated the reasons why virtually all our respondents had more than one social network account.

\begin{tabular}{|c|c|c|c|}
\hline Question & Options & Respondents & Percentage (\%) \\
\hline Why do you have & Access medium & 77 & 24.06 \\
\cline { 2 - 4 } $\begin{array}{c}\text { more than one social } \\
\text { network account? }\end{array}$ & $\begin{array}{c}\text { Distribution of } \\
\text { contacts }\end{array}$ & 220 & 68.75 \\
\cline { 2 - 4 } & Access restriction & 23 & 7.19 \\
\hline
\end{tabular}

Table 4 shows a cross-section of the responses we got to the question on "How often do you use your social network account?"

\begin{tabular}{|c|c|c|c|}
\hline Question & Options & Respondents & Percentage (\%) \\
\hline \multirow{2}{*}{$\begin{array}{c}\text { How often do you } \\
\text { usour social website } \\
\text { account(s)? }\end{array}$} & Daily & 242 & 75.62 \\
\cline { 2 - 4 } & Weekly & 42 & 13.13 \\
\cline { 2 - 4 } & Monthly & 21 & 6.56 \\
\cline { 2 - 4 } & $\begin{array}{c}\text { Once in two months } \\
\text { or longer }\end{array}$ & 15 & 4.69 \\
\hline
\end{tabular}

Table 5 is a representation of the values that we gathered in response to the question "What is your opinion on this? Is social network a curse or a blessing?"

\begin{tabular}{|c|c|c|c|}
\hline Question & Opinion & Respondents & Percentage (\%) \\
\hline \multirow{3}{*}{$\begin{array}{l}\text { What is your opinion on } \\
\text { this? Is social network a } \\
\text { curse or a blessing? }\end{array}$} & $\begin{array}{l}\text { Social network is a } \\
\text { blessing }\end{array}$ & 90 & 28.13 \\
\hline & $\begin{array}{l}\text { Social network is a } \\
\text { curse }\end{array}$ & 25 & 7.81 \\
\hline & $\begin{array}{l}\text { Social network is } \\
\text { neither a curse nor a } \\
\text { blessing }\end{array}$ & 205 & 64.06 \\
\hline
\end{tabular}


Table 6 contains values that were gathered from the response to the question "Which social network will you rank the best?"

\begin{tabular}{|c|c|c|c|}
\hline Question & Social networks & Respondents & Percentage (\%) \\
\hline \multirow{2}{*}{$\begin{array}{c}\text { Which social } \\
\text { network will you rank } \\
\text { the best? }\end{array}$} & Facebook & 160 & 21.88 \\
\cline { 2 - 4 } & Twitter & 70 & 25 \\
\cline { 2 - 4 } & 2go & 10 & 3.12 \\
\hline
\end{tabular}

\section{Results and Discussions}

From the data that was presented in Table 1 above, 192 of the respondents representing $60 \%$ of the sample population indicated that they use Facebook, 49 respondents representing $15.31 \%$ said they used Twitter, 69 respondents representing $21.56 \%$ said they use 2 go and 10 respondents representing 3.13 said they use other social networks like hi5, Naijapals, Eskimi and Gnaija.

From Table 2, 220 of the respondents, representing $68.75 \%$ of the sample population opined that they owned from 1 to 3 social network accounts, 85 respondents representing $26.56 \%$ indicated that they owned between 4 to 6 social network accounts while 15 respondents representing $4.69 \%$ indicated that they owned more than 7 social network accounts.

A look at Table 3 showed that 77 respondents representing $24.06 \%$ of the sample population indicated that access medium was the major reason that motivated them to owe more than one social network account, 220 respondents representing $68.75 \%$ opined that the reason why they have more than one account is because of the distribution of their contacts who are using other social networks, 23 respondents representing 7.19\% cited access restriction that they encountered at one time or the other as the motivating factor that made them to create and use different social network accounts.

From Table 4, 242 of the respondents representing $75.62 \%$ of the entire sample population said they used their social network account daily, 42 of the respondents representing $13.13 \%$ said they use their account once a week, 21 respondents representing $6.56 \%$ said they use their social network account(s) once in a month while 15 respondents representing $4.69 \%$ indicated that they use their social network account(s) once in two months less frequently.

Table 5 showed that 90 of the respondents representing $28.13 \%$ of the sample population indicated that Social network is in their opinion a blessing, 25 respondents representing 7.81\% agreed that Social network is a curse while 205 of the respondents representing $64.06 \%$ were of the opinion that Social network is neither a curse nor a blessing.

Table 6 showed that out of the sample population of 320 respondents, 160 respondents representing $50 \%$ said they rank Facebook as their best social network, 70 respondents representing $21.88 \%$ ranked Twitter as their best social network, 80 respondents representing 
$25 \%$ ranked 2 go as their best social network while a total of 10 respondents representing 3.12\% ranked any other Social network like Naijapals, Eskimi or Gnaija as their best in rank.

From the afore presented results, we were able to observed that all the respondents had more than one social network account for various reasons ranging from access medium, distribution of contacts to access restriction. Some of the respondents opined that they were having difficulty using some of their internet-enabled mobile phones to access some of their social network accounts like twitter. They complained that using their phones, access speed to twitter was very slow.

\section{Conclusion and Recommendations}

Arising from the findings of this work, is the fact that though a minimal size of the population $(7.81 \%)$ considered social networks as a curse, it is staggering to realize that an enormous size of the sample population (64.06\%) considered social network to be neither a curse nor a blessing. We were also able to discover that a colossal size of the sample population (75.62\%) make use of their social network account(s) on daily basis. We were also able to observe that $68.75 \%$ of the sample population which is quite large owned at least 1 or more social network account. Facebook turned out to be the social network of choice from our investigation as $60 \%$ of the sample population make use of it and $50 \%$ also ranked it as their best social network.

Social network can serve as a blessing or as a curse - it all depends on how you make use of them. In the past, social networking services were viewed as a distraction and offered no educational benefit. Blocking these social networks was a form of protection for students against wasting time, bullying, and invasions of privacy. In an educational setting, Facebook, for example, is seen by many instructors and educators as a frivolous, time-wasting distraction from schoolwork, and it is not uncommon to be banned in junior or high school computer labs. In the light of the aforementioned dilemma, one question that comes to mind is, "if we succeed to ban users from using these sites in public places, can we still ban them from gaining access to them in the privacy of their homes?" It is in an attempt to answer that fundamental question that we are recommending a review of those decisions to ban social networks. Instead of putting a ban on them, students and other would-be users should be properly educated on the proper use of these sites. Adequate enlightenment on some safety measures to adopt while using these sites should be enshrined in the regular school curriculum and other institutional manuals that will educate the user on the proper use of these social networks.

The number of users of social networks is growing by the day. It is often said that evil thrives in the absence of good. Against that backdrop, we are also recommending the development of more programs that will be beneficial to users in these social networks. This will help to provide a profitable diversion that will help the user to engage in more meaningful ventures in the social networks. 
It is also our sincere recommendation that security apparatus should be incorporated into all social networks to deter unwholesome behaviors and keep social misfits away from using social networks as a platform for carrying out their unscrupulous activities.

On a final note, social network users should never agree to meet online acquaintances in solitary places alone. The perils that such imprudent meetings can produce might far outweigh the perceived gains from such encounters.

It is hoped that as the aforementioned recommendations are embraced and implemented, we will be able to minimize the perils associated with social network usage while maximizing the full potential as inherent in social networks for the overall good of our world.

\section{Acknowledgments}

This research would not have been possible without the help of students at Auchi Polytechnic, Auchi, who mostly gladly accepted our questionnaires and responded to them timely. Our gratitude also goes to all our colleagues, friends and family members for their solidarity while we carried out this research. We are indeed grateful to all.

\section{REFERENCES}

[1]. Afia, E., Social Networks: Are They A Blessing Or A Curse? 2013 Retrieved from http://afiaenglish.wordpress.com/2013/03/14/social-networksare-they-a-blessing-or-a-curse-written-byafia-english/ on June 12, 2014.

[2]. Oyamienlen, G., Plan To Conquer Election Vises In July 14th In Edo State And Beyond - Phase One. 2012 Retrieved from https://www.facebook.com/notes/justice-oyamienlen-godfrey/plan-to-conquer-electionvises-in-july-14th-in-edo-state-and-beyond-phase-one-by/459052010788526 on May 3, 2014

[3]. Akinwale, A., Alleged Killers of Cynthia Osokogu Arraigned for Murder. ThisDayLive. 2013 Retrieved from http://www.thisdaylive.com/articles/alleged-killers-of-cynthia-osokogu-arraigned-for-murder/138927 on May 12, 2014.

[4]. The Associated Press May 1, 2013. Number of active users at facebook over the years. Retrieved from http://news.yahoo.com/number-active-users-facebook-over-230449748.html on November 27, 2013.

[5]. Hempel, J., "Linkedin: How It's Changing Business". 2013 Fortune. pp. 69-74.

[6]. Craig S., How Many People Use the Top Social Media, Apps and Services. 2013 Retrieved from http://expandedramblings.com/index.php/resource-how-many-people-use-the-top-social-media/ on January 3, 2014.

[7]. Douglas, B., Nicole, B. , Michael, F. and Caroline, V., Social Networking and Its Effects on Companies and $\begin{array}{lllll}\text { Their } & \text { Employees. } & \text { Retrieved }\end{array}$ 
Transactions on Networks and Communications; Volume 2, Issue 4, August 2104

http://www.neumann.edu/academics/divisions/business/journal/Review2011/SocialNetworking.pdf on March 15, 2014.

[8]. Wilson, J., Social networking: the business case. [Electronic Version] Engineering \& Technology 2009 (4)10 54-56.

[9]. Auchi Polytechnic, Student Handbook of Information, Published by The Information and Public Relations Unit 2011 p.4

[10]. Melissa, S., Demographic Breakdown Shows Who Uses Social Media Most. 2013 Accessed from http://socialnewsdaily.com/12711/demographic-breakdown-shows-who-uses-social-media-most/ on April 17, 2014. 